\title{
Practical teaching and learning evaluation of computational fluid dynamics based on traditional chemical engineering curriculum
} Junjie Chen*
School of Mechanical and Power Engineering, Henan Polytechnic University, Jiaozuc
*E-mail address: comcjj@163.com, comcjj@yahoo.com
ABSTRACT
Practical teaching and learning evaluation of computational id dynami
incorporated into a chemical engineering curriculum at the interm diave been
now become a component of professional life in engineering $\mathrm{p}$ ce and repare students properly, they must get exposure to all aspects of their chosen poression. Issuc /concern arise when mathematical modelling is being introduced into a curri flum. For example, at the practical level, it must be considered whether or not an appropriate platfe has been d/veloped to allow the students to use the software efficiently and importantly without tration. Ay o it is important that students have been taught sufficient skills for the student to cont with simulations in a systematic and methodical manner. The incorporation of the ackage into a traditional chemical engineering curriculum is described here, and evaluation resu and on pre-post knowledge and skill experiments, and student survey results documen s.cess $\mathrm{t} / \mathrm{l}$ learning outcomes and effectiveness of the approach.

Keywords: theoretical teaching $p_{1}$ earning evaluation; computational fluid dynamics; finite-volume method; trans ornd tion; marhematical modelling; engineering practice

\section{INTRODUCTICN Y}

The deve nent, in plementation and evaluation of a suitable curriculum for students to use utatio fl ad dynamics (CFD) as an extension of their chemical engineering kn ledge and skil at intermediate undergraduate level are described [1]. CFD is the sim. port phenomena, reacting systems, etc. using modelling, i.e. mathematical physica roblem formulation and numerical methods, which include discretization methods, solvers, $\mathrm{n}_{\mathrm{y}}$ crical parameters, and grid generation. Traditionally, in chemical engineering, formulation of mathematical models involves the solution of ordinary or partial differential equations to describe transport phenomena and reacting systems by incorporating analytical methods such as Laplace transforms or Fourier series expansions in Eigen functions [2]. Such methods are however restrictive, in that they usually require simple geometries and linear problems, whereas real chemical engineering problems can have very complex geometry and non-linear phenomena.

The use of mathematical modelling can now be found in many areas of engineering education, for example, for chemical reactions, for diesel engine simulation and in fluid 
mechanics and heat transfer [3]. Some work has also been carried out in developing educational user-friendly CFD interfaces where the general aspects and simplification of the three main processes of CFD, the pre-processor, the solver and the post-processor were carefully considered [4]. However, although the educational benefits associated with integrating computer-assisted learning and simulation technology into undergraduate engineering courses are great, and computational fluid dynamics has revolutionized research and design, its incorporation into the teaching of undergraduate transport phenomena has been limited. This lack of penetration of CFD into the undergraduate curriculum is probably primarily due to a deficiency of faculty with training in CFD, the lack of knowlodre by faculty of educational CFD tools available and the start-up time associated witb cevelo, educational CFD materials.

Why should CFD be included in an undergraduate chemical enginenring riculun The answer is that CFD is now to a lesser or greater degree part of the profession ves of many chemical engineers and so, to prepare future engineers $p$ erly, ey $m$ get exposure to all aspects of their chosen profession [5]. In the are 0 aysis a design, simulation based design is commonly used instead of the tradit onal "buh nd to st", as it is much more cost effective and a substantial database is proy a or diagno of the adjacent flow field. Simulations can readily be done of physical flo phen ena that are difficult to measure, for example, full scale situations, and eny onmental efl and importantly in chemical engineering hazards. Problem solving with nodern engineeri $/ \mathrm{g}$ tools, such as found in CFD, can be applied to realistic problems [6].

Issues of concern arise when simulation is be introduc ed into a curriculum. These include learning vs. research objectives, urability vs. demographics. A proper balance should be between these competing objectives, for example, it is just as important that a studen be auro the practical and systematic ways of using a CFD package in a general conse, as 11 as achieving a specific result [7]. There is much evidence from previous adio hat: the use of simulation enhances the curriculum; there is increased learning $e^{f}$ ancy and unde standing; there is effectiveness of new and hands-on learning metho an to use a combination of physical and simulation laboratories

Practical conc ns cerning introduction of CFD are for example, when to introduce, how m co int and how much CFD background is necessary. There is no doubt that whe a student first $\mathrm{CFD}$, a lot of new knowledge and required skills descend on them fre man jirections hence rendering a steep learning curve. Without careful planning this can be me overwhelming. Also, importantly, it is essential that students do not 'feè ' fo physical and chemical phenomena, needed assumptions used in mat' emat 1 mode $\mathrm{g}$, nor the need to verify and validate the computational methods app. to mobl $\mathrm{cm}$. This is a common concern when introducing mathematical modelling, for exa Te process simulation software. Successful implementation of CFD usually requires a re-focus course objectives and skills taught and a re-structuring of the course curriculum. An important concern is that students adapt a healthy skepticism as to the results they get and a willingness to be critical of the results should be instilled into them.

In the rest of this paper how computational fluid dynamics is implemented into the chemical engineering curriculum is first described. The next section presents evaluation design, results and discussion, in the form of three investigations, one an experiment comparing the students' knowledge of chemical engineering before and after their CFD course, one measuring the student learned knowledge and skills regarding the CFD interface 
and one eliciting student views on using CFD by questionnaire. The paper finishes with conclusions drawn and possible work for the future.

\section{TEACHING IMPLEMENTATION}

Computational fluid dynamics was introduced to students of chemical engineering in the form of necessary back-ground theory lectures, tutorials and hands-on laboratories. The course was held over a 4-week period, with the theory taught intensively during the of the course and as required during the last 3 weeks. Hands-on laboratory essions th conducted throughout the final 3 weeks with students given short demonstratio where the watched the instructor building simple simulations while doing the sme on eir oy computer, completing simulations using highly detailed instruction she cts fu'v supp by faculty and teaching assistants, and finally solving problems withe vstr ctions and only occasional help from support staff [9].

The students had already successfully completed cour on mati vora, vector calculus, ordinary differential equations and partial diffe entio quations, with the latter being solved using a variety of numerical methods [1 Shey also been exposed to courses on fluid mechanics, thermodynamics and cher ilcal processes.

The main learning outcomes are to understa $d$ the equations that govern fluid flow (conservation of mass, momentum, species, and ene v) and be a le to apply them to a range of practical problems in the areas of fluid flow, hea nsfer a chemically reacting flows.

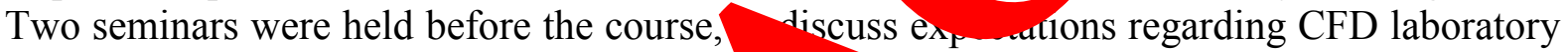
practice and reporting. During these semina s, ments were introduced to the idea that theoretical chemical engineering, experimenta $c^{\prime}$ emig, engineering and computational fluid dynamics are complementary in $p$ engin ering practice. Students were then introduced to CFD general methodology a pro dures. T/students learned as to when and why CFD is used, and the breakdown th $\mathrm{j}$, processes namely the pre-processor, the solver and the post-processor. $\mathrm{T}$ e studen oup was then initiated to CFD with an intensive 1-week course outlining theor good pra $\%$ The course followed the headings of,

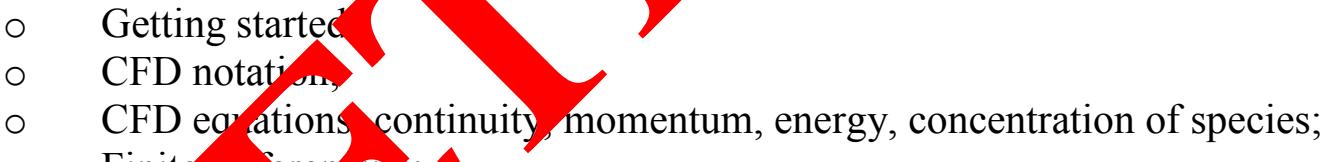

- Finite serencing;

- The finite ume $m$ ihod;

- 200 ary co tions;

Acco inting for the pressure term;

o eraged equations;

○ $\mathrm{T}$-stepping techniques; and

- Prop Mes of numerical methods.

The theory course also included good practice and showed students the need for CFD methodology to be systematic and rigorous. It was pointed out that the complete process, at this level of CFD can, if so desired, be completely automated with the students going through a step-by-step process seamlessly from the set-up of the problem, through the solving to the display of the results without much thought. Importantly then, the students were taught to be critical of their results and how to examine if what they were getting is what they might have expected. 
The general process of solving using CFD techniques, which the students were encouraged to strictly adhere to in this early stage of their CFD studies.

As mentioned above, the laboratory part of the course started with a series of demonstrations with full facilities for students to have 'hands-on' experience as the demonstration proceeds. Several simple three-dimensional flows are used as exemplars to give an overall view of the CFD process. A period of time was always given so students could go back to different stages of the process to experiment either by themselves or with suggestions from the faculty and teaching assistants. Gradually students moved on to working by themselves, first with provided detailed instructions, then to semi-detailed instructinn and finally only to specifications of the problem to be solved.

A brief description of the course material used during the 'hands-on' ction of course is now given. Three relatively easy exemplars were first used, name ${ }^{1}$, an roductic to setting-up flow problems, adding heat transfer to the calculation dom ain and, ro ing ne computational grid in the flow domain. These were slowly and caref $\mathrm{y}$ den ystrate with the students processing each described step on their individual con uu nis wa followed by six major simulations, namely,

○ Importing geometry into the calculation domain

It is important that students are comfortable impontis geo try generated elsewhere into the calculation domain. This geometry could be in an, built us oy a computer-aided drawing (CAD) package or an in-house computer $\mathrm{p}$ ogram. In this exprise a NACA 4-digit 2D aerofoil was generated and imported.

$\circ \quad$ Flow and heat transfer in a mixing elbow

In this, students set-up and solved a three-dimen arbulent flow and heat transfer problem in a mixing elbow. The mixing elb figuration is used in piping systems in the process industry and it is often important to orre $h$ dict the flow and temperature fields in the mixing region.

$\circ \quad$ Modelling species transpo ano iseous a mbustion

The mixing of chemical cies nd the combustion of a gaseous fuel is examined here. A cylindrical combustor $b$ ing manced $A_{4}$ ) in air is studied using the eddy-dissipation model. The exercise $\mathrm{w}^{\mathrm{i}}$ - 1 llow for prediction of the thermal field and for the production of $\mathrm{NO}_{x}$.

- Using the nomix ombustion model

Here, a atural gas com stion problem is set and solved using the non-premixed combustion odel the reaction chemistry. The non-mixed combustion model uses a modelling app a which solves transport equations for one or two conserved scalars and the mi fract $\mathrm{Pr}$ perty data for the species are accessed through a chemical database and urbu ce-chen ary interaction is modelled using a probability density function mixture frac - Telling surface chemistry

In aically reacting laminar flows, such as those encountered in chemical vapour deposition (CVD) applications, accurate modelling of time-dependent hydrodynamics, heat and mass transfer and chemical reactions, including wall surface reactions, is important.

○ Modelling evaporating liquid spray

An air-blast atomizer model is used to predict the behaviour of an evaporating methanol spray. Initially, the air flow is modelled without droplets. To predict the behaviour of the spray, several other discrete-phase models, including collision and breakup are used. 


\section{TEACHING AND LEARNING EVALUATION}

The CFD course was taught in the fourth semester of a chemical engineering undergraduate degree course with the number of students in the group. The evaluation process was subdivided into three investigations, one in the form of an experiment comparing the knowledge of the group concerning chemical engineering and related mathematics before and after their CFD course, the second measuring student knowledge and skill outcomes for the CFD interface, again before and after their CFD course, and, the third in the form of an online questionnaire eliciting the views of students on using CFD.

\subsection{Effectiveness of using CFD for chemical engineering teaching and lea \\ To investigate the effectiveness of introducing CFD into the course, an experiment applying a pre-test post-test design was students' knowledge and skills outcomes in the form of th significantly higher than their pre-test scores. Implementin this sun tive evaluation} required an objective measure of student outcomes in at lea on urricular a of chemical engineering with the areas chosen here being heat and $m$ s ransi nd chemically reacting flows. A pool of assessment questions covering these wo areas was assembled and then paired for equivalency following a Table of Specifi ation by the instractional staff [11]. The dependent variables are constructs used to capture a cts of learl ing provided by the courses and each was measured using three or more questions

One concern was that students simpl memberen topics tested during the pre-test and concentrated on learning those better du ing course and thus did better over the same topics even though they may not have le r.ed the outcomes properly. So, topics in each pair were randomly assigned to $\mathrm{n}$ A or version of the pre-test and at the same time students were randomly assio do ther the $A$ or $B$ version of the pre-test which they completed. For the post-te the pleted both the A and B versions. To be clear, all students completed 9 a a A or version for the pre-test, but took both the A and the B for the post-test.

\subsection{Student krowledge and s outcomes for the CFD interface}

An obje measur of student knowledge and skill outcomes for the CFD interface as applied the ch ical ngineering curriculum was devised. This test was again run on pre/ ost $\mathrm{D}$ studio oasis, i.e. during the first week of the course students completed the pre a the semester, and after completing the CFD studies, the students complo the post-test. The most intuitive test of students' knowledge and skill outcomes is whether $\mathrm{t}$ bst-test scores were significantly higher than those of the pre-test scores. It can be seen that the effect is substantial between pre- and post-tests and therefore represents significant improvement in outcomes of the students' knowledge and skills of CFD knowledge and skills [12]. The students, after a relatively brief exposure to and with limited practice of CFD have shown considerable growth in their understanding of CFD concepts, principles and applied problems. 


\subsection{On-line questionnaire}

An anonymous online survey was conducted after students obtained their grades for the laboratory reports to aid formative evaluation of the introduction of CFD. The survey was in two parts, with one part the students' feeling regarding how well they were prepared for the introduction of CFD into their curriculum and the other exploring their opinions on the skills and knowledge acquired when using the actual computer package [13]. Students were requested to respond to each item in the questionnaire using a five-point scale: strongly agree, agree, neutral, disagree and strongly disagree plus a column for no opinion. An opmominity was also provided for students to comment on their experience at the end of the to collect qualitative feedback on their experience so far with CFD. Students fo that they $\mathrm{h}$ been reasonably prepared for and benefited from their exposure to CDD. ddition comments most of the students expressed the view that the amount 0 material du ed was correct, although some felt that the exercises took a long time com ecte co ctly. Students were particularly appreciative that they could easily vi ali of of usir contour and vector plots and generally agreed that the combination of $t$ eory, exp nent 1 and CFD led to better understanding of fluid mechanics [14]. Stude is vo showe athusiasm for learning more about CFD.

The students indicated that their previously gorca knowlea algebra and vector/tensor calculus was sufficient an that their existip knowledge of PDEs was adequate. However, for PDEs comments wer nade that they did need to revise their previous course in that some details had been forgot More problematic was the responses given by the students regarding the therry needed. ocretization of the equations. Basically the thought was that the backgrou rasonably interesting did not contribute to the use of the CFD package. Mos sm its felt that more worked examples would be a good innovation. Therefare, mor development will be necessary to bridge the obvious gap between the theor ano ractice fCFD. Generally the students were of the opinion that they were now ac lainted y ith some of the important aspects of CFD practice, that is using ty en roum. implementing suitable boundary and initial conditions and the imp ant mathe tical aspects of grid independence and when and how to implement under-

It was noted the su the liked the hands-on and self-discovery approach, although at times some fustration was a noted. Once a demonstration was given there was only an interest to le by th selves, backed up when required by a teaching assistant's advice [15]. The traditiona $~ w$ of $C l$ is that it has a steep learning curve, but with a structured CFD interfar nd, whit depth imposed, it has been demonstrated that the gradient of the cur can brough on acceptable level.

Dur as the pose was to develop users of the code only. This can be remedied by a later course which in, es the student as a user and starts showing ways of writing new codes for special conditions.

\subsection{Instructor views}

The following is a brief summary of views of instructors concerning introducing computational fluid dynamics into a chemical engineering curriculum. One concern was to ensure proper under-pinning understanding of the mathematical aspects of computational fluid dynamics, which involved an intensive course, mainly centered primarily on 
mathematical numerical methods. It should be recognized that for some chemical engineering students such a course is quite challenging and perhaps a longer, more leisurely course may be better for learning [16]. Some topics introduced are by necessity advanced, for example "accounting for the pressure term". The course should also be very systematic without many assumptions being made of student prior knowledge and delivered with much interaction and feed-back from the students. However, it is thought that although having hurdles to overcome, it is thought that the best approach for intermediate level undergraduate students is to teach a reasonably deep and broad range of numerical methods leading to CFD theory so giving a sound basis for the later methodology and procedures.

While lectures and laboratory course teaching seemed to work here, there $\mathrm{j}$ a case towards the end of the course some studio and/or multi-media may need to b leveloped that students can think and work at their own pace and alone, with only ocmion help fro written instructions and instructing staff [17]. This has the benefits of re'acing the etin es considerable work-load imposed on the instructing staff and also reasin the st ents' confidence and willingness to experiment [18].

There can be a steep learning curve associated with CFD iterfaces. is im, ortant that time is taken to carefully allow the students to become famili a sometì quite hidden, interface windows necessary for setting calculations up rects 19]. Much practice and experimentation by the students is worthwhile, so gene atm. confiden reducing student frustration. A problem instructors should be aware $f$, is that all studjuts do not come with the same background knowledge and skills rega ling the us of modern interfaces. If necessary, a separate hands-on course should be offe in this ar ca [20].

Traditionally a CFD curriculum has focused on cvelopment while not training component users, as is the purpose in this $\mathrm{w}$ traditional approaches, students are asked to either partly or completely develop the oy research code using CFD theory learned. It is though that this is not necessary this sage of CFD user training but a subject for post-graduate studies.

It is the view of the in ting staff that the use of computational fluid dynamics to simulate various chemical in g andow allowed the students to more easily explore and understand some b? ss concep. ught in the traditional course. The use of colour in the graphical representa on lows for easy visualization of the phenomena, which can significantly facilin and $\mathrm{nce}$ the learning process. Also, the students can more easily explore the efects of chang the simulation conditions without requiring additional physical lab tory $f$ eriments. In addition to varying the chemistry, geometry dimensions or configuratio an be re tivity easily varied.

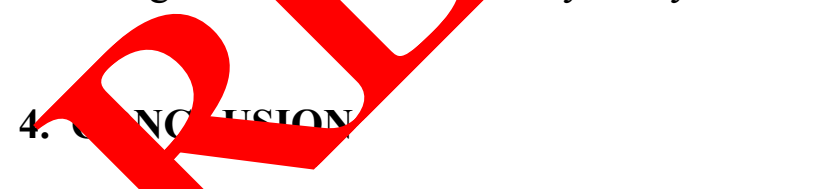

Thy her has described the use and efficacy of incorporating computational fluid dynamics into a traditional chemical engineering curriculum. The experiment has shown that the inclusion of CFD gave students a better appreciation of chemical engineering in general and the students gained better knowledge of simple concepts. It was found from the study of student knowledge and skill outcomes for the CFD interface that the students could cope with CFD reasonably well, provided the subject is introduced with care. One of the main reasons for the inclusion of CFD was to contribute to the teaching of professional practice skills to intermediate level undergraduate students. It was found that the interface design does provide students with hands-on experience, gained through an interactive and user-friendly 
environment, and encourages student self-learning. It was noted from the survey that the students liked the hands-on and self-discovery approach, although at times some frustration was also noted.

The success of the present work encourages future development in this area of the curriculum with inclusion of more examples found in chemical engineering. There was evidence that more time should be spent on the theory underlying CFD, especially in the area of finite differencing of equations, as well as emphasis should be placed on, and more opportunity provided, for students to verify and validate their results. The assembly of a strong centralized database for comparison would be desirable. Again the idea of obtaining a grid independent solution should be reinforced.

\section{References}

[1] Arslan A.A., An Analysis of Teaching Methods Used at the Co rso asic De in. Procedia - Social and Behavioral Sciences 51(0) (2012) 17 -176.

[2] Ruskovaara E., Pihkala T., Seikkula-Leino J., Järvinen 1.R., 'oadening ne resource base for entrepreneurship education through teachers euvorkin ctivities. Teaching and Teacher Education 47(0) (2015) 62-70.

[3] Al-Qirim N., Determinants of interactive white ard successin teaching in higher education institutions. Computers \& Education (3) (2011) 827-838.

[4] Aelterman N., Vansteenkiste M., Van Kr.H., De J., Van den Berghe L., Haerens L., Development and evaluation of a tra thon need-supportive teaching in physical education: Qualitative and quantitative fii dip gS. Iy ching and Teacher Education 29(0) (2013) 64-75.

[5] Bullough Jr R.V., Ethical mo 1 matters $n$ teaching and teacher education. Teaching and Teacher Educatior 77,

[6] Kelly J., Watson R in integrau review of the literature on the teaching of the history of nursing in pre regi tion aduly nursing education in the UK. Nurse Education Today $35(2)(2015)$ ? 365 .

[7] Orland-P rak L. Mediation In mentoring: A synthesis of studies in Teaching and Teacher. 180 188. $T$ ching and Teacher Education 44(0) (2014) 180

[8] Ch M.M. Cha K.-W., Tang S.Y.F., Cheng A.Y.N., Pre-service teacher education studen episten ogical beliefs and their conceptions of teaching. Teaching and hon 25(2) (2009) 319-327.

[9] de J.M.A., Timmins F., Psychology teaching in nursing education: A review of and reflec $A$ on approaches, issues, and contemporary practice. Nurse Education in Practice 12(6) (2012) 316-321.

[10] Martin K.J., Student attitudes and the teaching and learning of race, culture and politics. Teaching and Teacher Education 26(3) (2010) 530-539.

[11]Rots I., Aelterman A., Devos G., Vlerick P., Teacher education and the choice to enter the teaching profession: A prospective study. Teaching and Teacher Education 26(8) (2010) 1619-1629. 
[12]Rots I., Aelterman A., Vlerick P., Vermeulen K., Teacher education, graduates' teaching commitment and entrance into the teaching profession. Teaching and Teacher Education 23(5) (2007) 543-556.

[13]Kleinsasser R.C., Teacher efficacy in Teaching and Teacher Education. Teaching and Teacher Education 44(0) (2014) 168-179.

[14] Tigchelaar A., Korthagen F., Deepening the exchange of student teaching experiences: implications for the pedagogy of teacher education of recent insights into teacher behaviour. Teaching and Teacher Education 20(7) (2004) 665-679.

[15]Häfner P., Häfner V., Ovtcharova J., Teaching Methodology for Virtual Reg ity Pracı Course in Engineering Education. Procedia Computer Science 25(0) (20 51-260.

[16]Charalambous C.Y., Komitis A., Papacharalambous M., Stefanou A Joing go content-specific teaching practices in teacher evaluation: An explo atory dy or teachers' perceptions. Teaching and Teacher Education 41(0) ( $20,22,33$.

[17] Akhmetova J.B., Kim A.M., Harnisch D.L., Using Mixed y thods to dy F motional Intelligence and Teaching Competencies in Higher Edur tio Procedia, ocial and Behavioral Sciences 128(0) (2014) 516-521.

[18] Smith P., Allan T.H., "We should be able to bear our patients in ou reaching in some way": Theoretical perspectives on how nurse te hers manage their emotions to negotiate the split between education and caring actice. Nu se Education Today 30(3) (2010) 218-223.

[19] Gorski P.C., What we're teaching teache analysis of multicultural teacher education coursework syllabi. Teaching od Tean Education 25(2) (2009) 309-318.

[20]Chen C.-P., Lai H.-M., Ho C Yhy do achers continue to use teaching blogs? The roles of perceived voluntar ess a, habit. mputers \& Education 82(0) (2015) 236249 .

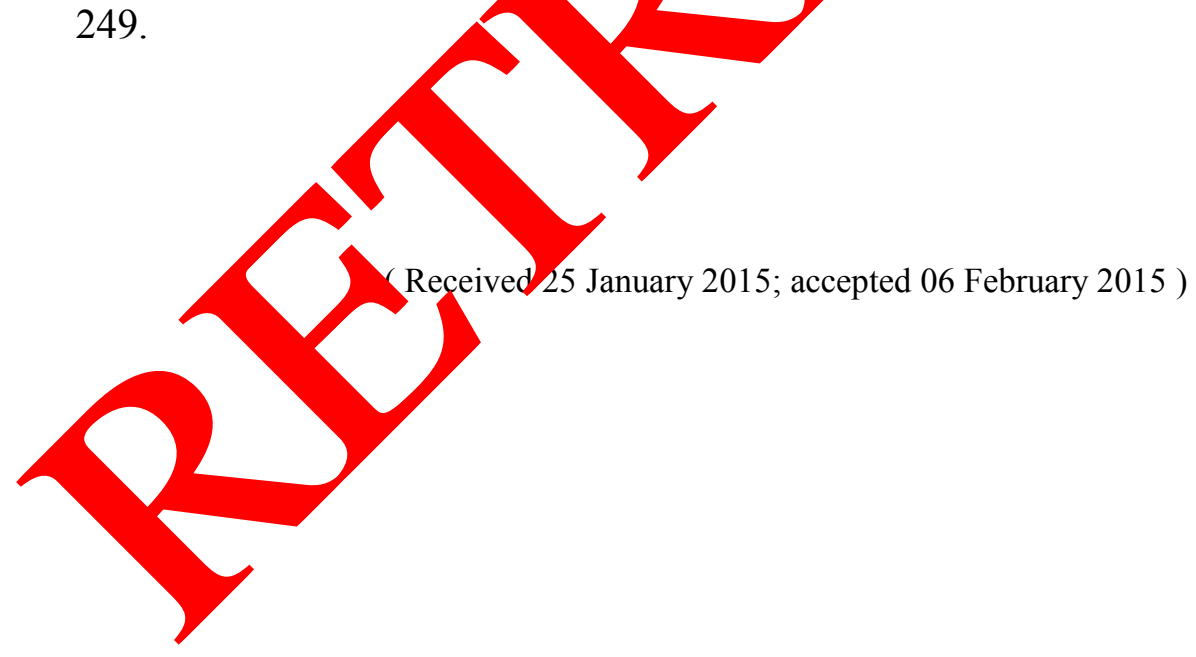

